\title{
Study of Combined Effect of Inclination and Partial Fins on Melting of Phase Change Material in A Rectangular Enclosure Using CFD
}

\author{
D. Kondala Rao*, Srinivas Kolla, C. Tara Sasanka, D. Sameer Kumar
}

Department of Mechanical Engineering, R.V.R. \& J.C. College of Engineering, Guntur, Andhra Pradesh, India

* Corresponding author email: kondalmech@gmail.com

Received: 22 December 2018 / Accepted: 28 December 2018 / Published: 31 December 2018

\begin{abstract}
This study presents the combined effect of inclination and internal fins on melting rate of PCM in a rectangular enclosure $(8.89 \mathrm{~cm} \times 6.35 \mathrm{~cm})$. Rectangular enclosure has a hot wall with a temperature of $311 \mathrm{~K}$, a cold wall with a temperature of $301.3 \mathrm{~K}$ and the other two walls are insulated. Gallium with very low prandtl number is taken as the PCM in this study. First, the individual effects of different inclinations $\left(0^{\circ}, 45^{\circ}\right.$ and $\left.90^{\circ}\right)$ of the enclosure on melting rate of PCM are studied followed by the study of the effect of internal fins. Then we provide a combined environment of inclination and partial fins and obtain the results of liquid fraction, velocity contours and temperature distributions. Plots for liquid fraction and average temperatures with respect to time are also obtained. Finally, the results and plots of combined effect are compared with those of other conditions. From the comparison we conclude that combined effect of inclination and partial fins under constant normal gravity condition greatly enhances the heat transfer in PCM.
\end{abstract}

Keywords: Computational Fluid Dynamics; Phase Change Materials; Thermal behaviour; Partial Fins.

\section{Introduction}

Phase change materials (PCM) are of growing interest nowadays as thermal energy can be stored in PCM as sensible heat by raising its temperature or as latent heat during the phase change process. PCMs have high energy storage capacity and isothermal behavior in melting and solidification processes. There is a wide range of applications for PCMs such as refrigeration [1], storage of solar energy [2], buildings [3], desalination [4], thermal stability of electronics [5] and many more. In order to enhance the heat transfer mechanism of systems using PCMs, a thorough understanding of the thermal behavior of the PCM is required. Number of techniques have been developed in order to increase the thermal performance of PCMs which include the use of high conducting materials, the extended heat transfer surface [6], the use of intermediate heat transfer medium, the heat pipes, the multiple PCMs [7], the micro-encapsulation [8] and so on. One of the two major heat transfer enhancement techniques in PCM are providing partial fins [9] and giving inclination to the enclosure [10]. It has been established by previous studies that these two techniques enhance the thermal performance of PCMs. But there are very few or no studies on the combined effect of partial fins and inclination on thermal performance of PCMs. In this study the combined effect of partial fins and inclination on thermal performance PCMs under constant gravity conditions is compared with their individual effects.

\section{Progression of the Study}

Firstly, the melting of PCM under normal conditions is studied. Then, the individual effect of partial fins and inclination of the enclosure are studied. For the case of inclination we only take the case of horizontal hot wall $\left(90^{\circ}\right.$ inclination) because the heat transfer enhancement for the horizontal enclosure is higher than 
that of any other inclined configuration. Finally, both partial fins and $90^{\circ}$ inclination are provided to the enclosure containing the PCM and the results are compared with all the individual effects.

\section{Modelling Phase Change Materials}

Phase-change processes (melting and solidification) are modelled primarily in three different ways; empirical, classical and enthalpy-based methods. In the empirical method, higher conductivity values are assigned for the liquids to account for convection effects and purely conduction treatment is considered. Classical method accounts for the convection by solving suitable governing heat and mass transfer equations. Enthalpy-Porosity technique [11] is widely followed now-a-days to model solidification/melting problems which uses the latent heat and assigns every computational cell a nodal latent heat value according to the temperature. When a phase-change occurs in the material (computational domain), the latent heat value is adjusted accordingly. In this method, instead of tracking melt-interface, liquid fraction, which is the liquid fraction of cell volume, is assigned to each cell in the domain. Liquid fraction is computed at each iteration through which energy source term is obtained.

We assume boussinesq model to be valid in our problem. This model treats density as a constant value in all solved equations, expect for the buoyancy term in the momentum equation. Thus, along with momentum sink term we add buoyancy source term (boussinesq treatment) to account for naturalconvection effects. In this work

Enthalpy-Porosity technique is modelled using FLUENT 15.0 CFD code. The governing heat transfer and fluid flow equations are:

Mass conservation equation: $\frac{\partial \rho}{\partial t}+\nabla \cdot(\rho V)=0$

Momentum equation: $\rho \frac{D \vec{V}}{\partial t}=-\nabla p+\mu \nabla^{2} \vec{V}+\rho g+\vec{S}$

Energy conservation equation: $\rho \frac{D h}{\partial t}=\mathrm{k} \nabla^{2} T$

Where, $\varrho$ is the density, $\mathrm{k}$ is the thermal conductivity, $\mu$ is the dynamic viscosity, $\vec{S}$ is the momentum source term, is velocity vector, $\mathrm{T}$ is temperature and $\mathrm{h}$ is specific enthalpy. Other auxiliary equations are prohibitively long to mention here, and therefore can be found in Ref. [11].

In this study we consider a 2-dimensional rectangular computational domain of dimensions $8.89 \mathrm{~cm} \times$ $6.35 \mathrm{~cm}$. A uniform mesh of $42 \times 32$ node in $\mathrm{x}$ - and $\mathrm{y}$ - directions is used. Gallium is used as the PCM. Thermo-physical properties of gallium used in the simulation are listed in the table.1.

Table 1: Thermo-physical properties of Gallium

\begin{tabular}{|c|c|}
\hline Property & Value \\
\hline Specific heat capacity & $381.5 \mathrm{~kJ} / \mathrm{kg} \mathrm{K}$ \\
\hline $\begin{array}{c}\text { Melting temperature } \\
\text { (Reference) }\end{array}$ & $302.78 \mathrm{~K}$ \\
\hline Latent heat of fusion & $80160 \mathrm{~J} / \mathrm{kg}$ \\
\hline Thermal conductivity & $32 \mathrm{~W} / \mathrm{m}-\mathrm{K}$ \\
\hline Density (Reference) & $6095 \mathrm{~kg} / \mathrm{m} 3$ \\
\hline Dynamic viscosity & $1.81 \mathrm{E}-3 \mathrm{~kg} / \mathrm{m}-\mathrm{s}$ \\
\hline $\begin{array}{c}\text { Volume thermal expansion } \\
\text { coefficient of liquid }\end{array}$ & $1.2 \mathrm{E}-4$ \\
\hline Prandtl Number & $2.16 \mathrm{E}-2$ \\
\hline
\end{tabular}


Rao et al., J. Mod. Sim. Mater.; Vol. 1 Issue 1, pp: 30-38, 2018

In this study, four cases are simulated, and results are analysed: 1) melting of gallium in normal conditions of the enclosure 2) with the enclosure inclined at $90^{\circ} 3$ ) with partial internal fins and 4) both inclination and partial internal fins (all the cases with normal gravity).

The temperatures of hot wall are fixed at $311 \mathrm{~K}$ and that of cold is fixed at $301.3 \mathrm{~K}$. Other walls are insulated. The PCM is considered to be at $301.3 \mathrm{~K}$ initially and simulations are conducted with normal gravity. Fig (2), comprises of four internal fins, each with a length of $1.0 \mathrm{~cm}$ and height of $0.71 \mathrm{~cm}$.

Monitors are created for liquid fraction and average temperature of the enclosure as the time progresses. Vertex average of liquid fraction and average temperature of each element of the computational domain is calculated and plots are generated with time (seconds) on $\mathrm{x}$-axis.

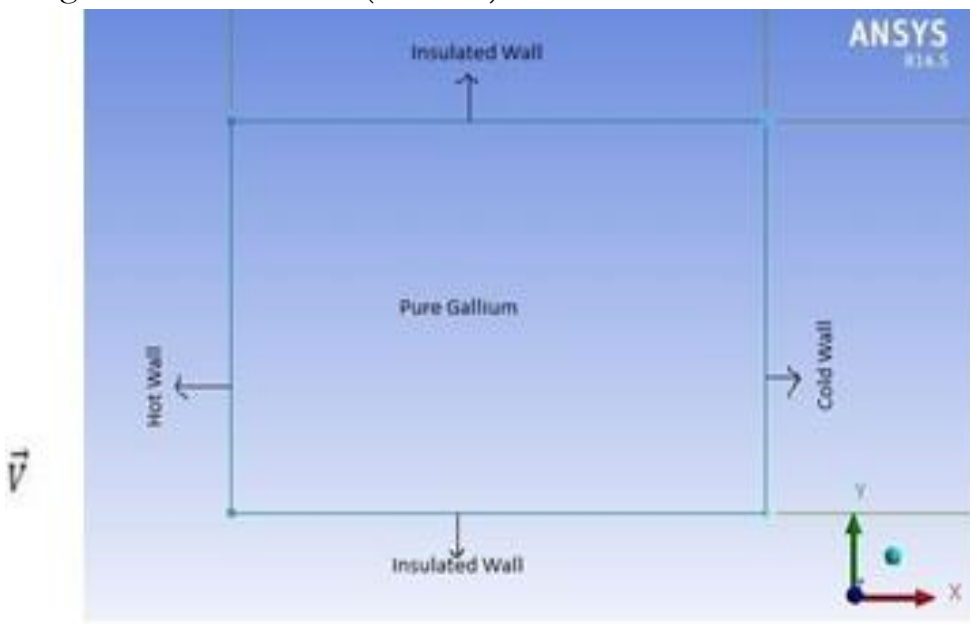

Figure 1: Computational domain without fins.

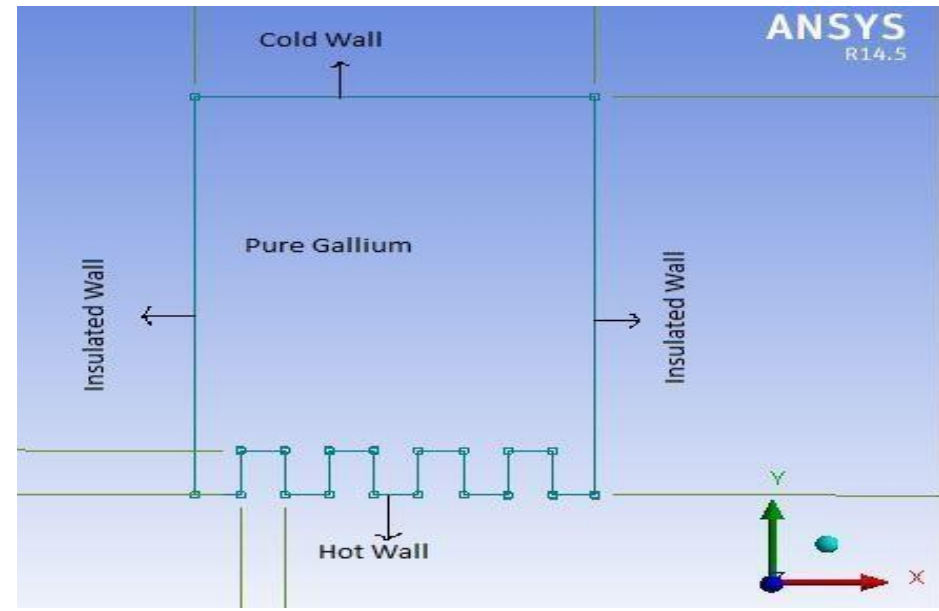

Figure 2: Computational with $90^{\circ}$ inclination and partial fins.

The computational domains for case (2) and case (3) are the derivatives of Fig2.So they are not shown separately.

\section{Results and Discussion}

Figures $(3,6,9,12)$ show the advancement of solid-liquid interface, streamlines and temperature distribution. Fig3 for normal conditions, Fig4 for inclined enclosure, Fig5 for the enclosure with partial fins and Fig6 for the combination of inclination and partial fins, at different melting times, $\mathrm{t}=180 \mathrm{~s}$ (Fig. 3,7,10,12a, d, g), $t=360 \mathrm{~s}$ (Fig. 3,7,10,12b, e, h), and $\mathrm{t}=540 \mathrm{~s}$ (Fig. 3,7,10,12c, f, i).

During the melt down of Gallium in the enclosure, initially, conduction dominant melting occurs along the hot wall resulting in uniform propagation of melt interface as the viscous forces oppose the movement of the liquid PCM. Later the thickness of the liquid at the top of the enclosure increases due to which mobility increases leading to the domination of buoyancy forces over viscous forces. Buoyancy forces trigger the 
Study of Combined Effect of Inclination and Partial Fins on Melting of Phase Change Material................................ Using CFD

natural convection currents in the enclosure. This being said, we can say from velocity contours that the liquid rises along the hot wall and crawls down along the melt interface causing clockwise currents.

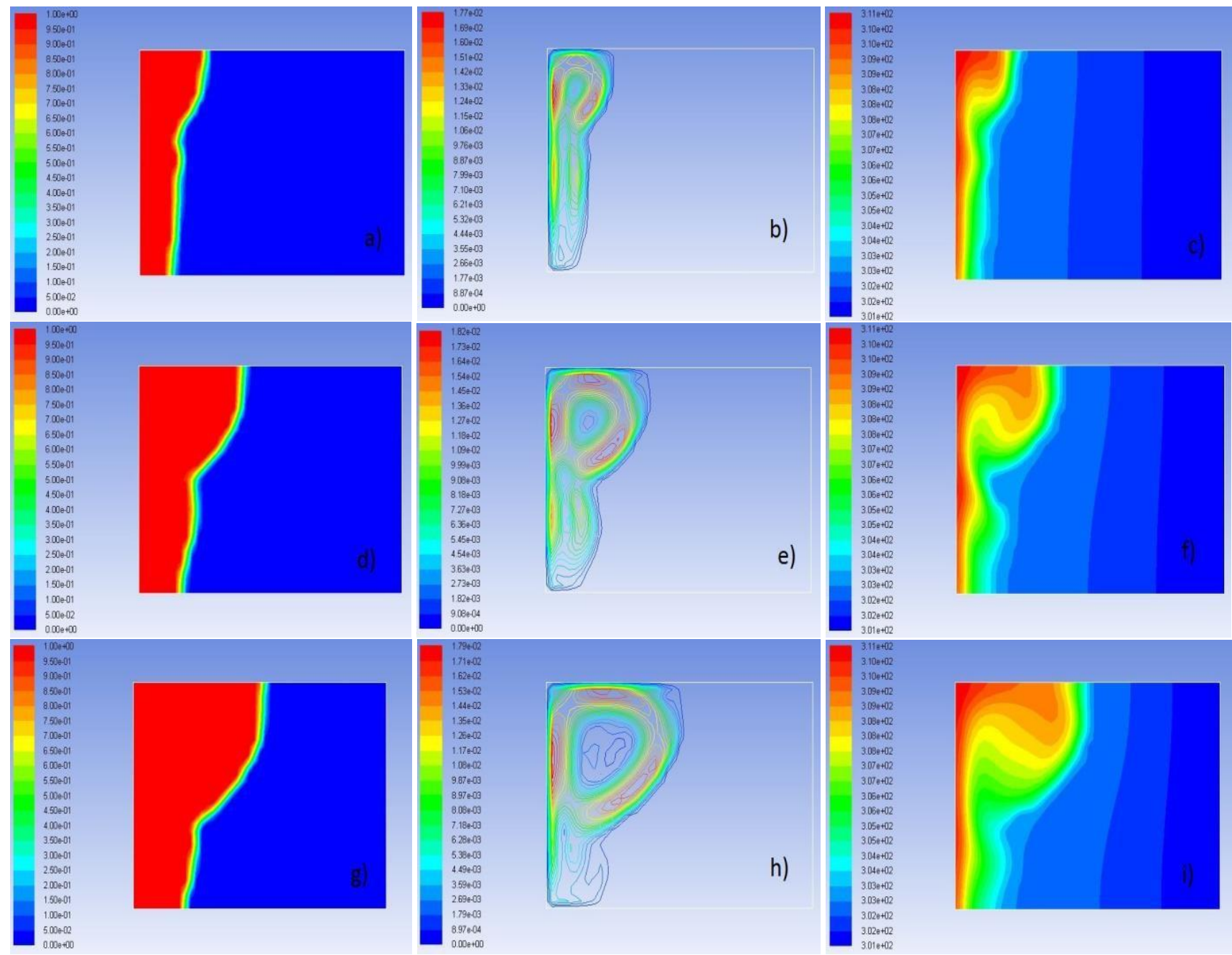

Figure 3: Melting of gallium under normal conditions, after time, $t=180 \mathrm{~s}($ top), $360 \mathrm{~s}$ (middle) and $540 \mathrm{~s}$ (bottom); $(a, d, g)$ are solid-liquid interface propagation, $(b, e, h)$ are stream lines and $(c, f, i)$ are isotherms.

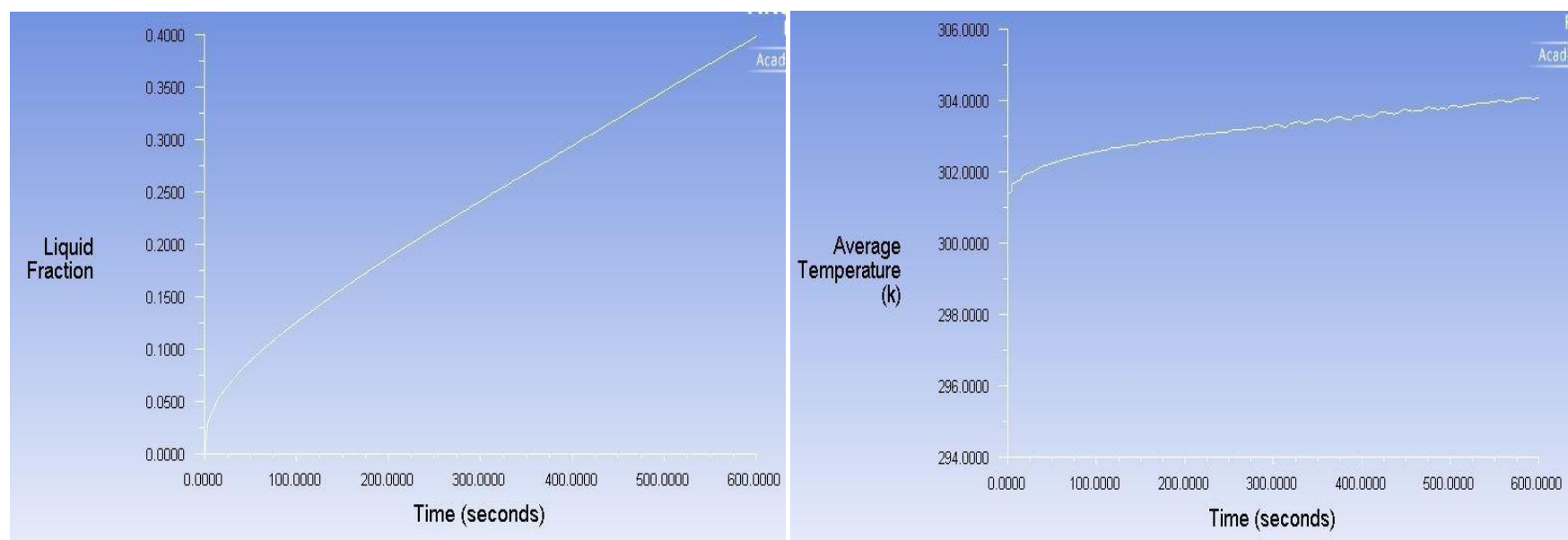

Figure 4: Liquid fraction vs time graph for melting of Gallium under normal conditions.
Figure 5: Average temperature vs time graph for melting of Gallium under normal conditions. 
Rao et al., J. Mod. Sim. Mater.; Vol. 1 Issue 1, pp: 30-38, 2018

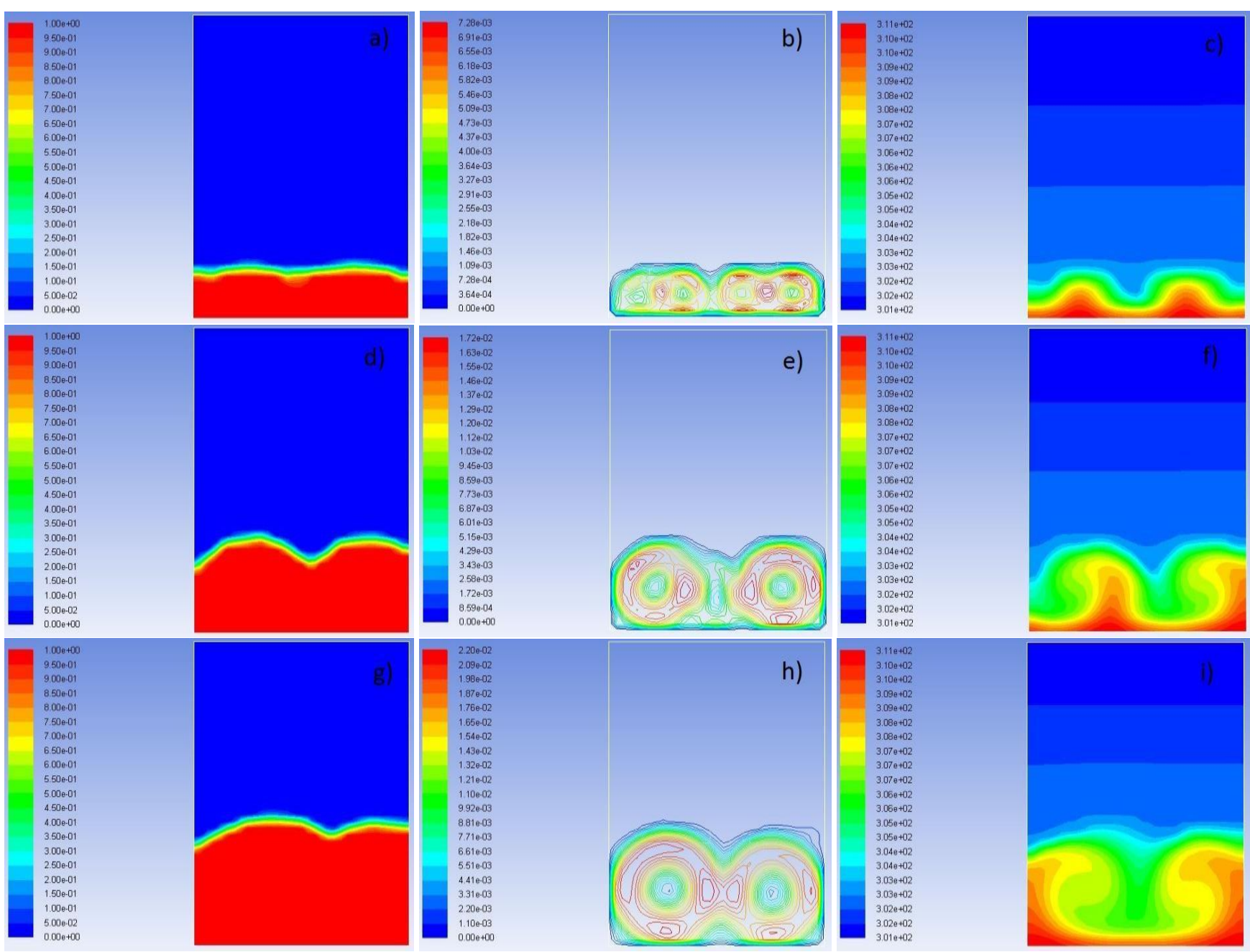

Figure 6: Melting of gallium in an enclosure inclined at $90^{\circ}$, after time, $t=180 \mathrm{~s}$ (top), $360 \mathrm{~s}$ (middle) and $540 \mathrm{~s}$ (bottom); ( , $d, g)$ are solid-liquid interface propagation, $(b, e, h)$ are stream lines and $(c, f, i)$ are isotherms.

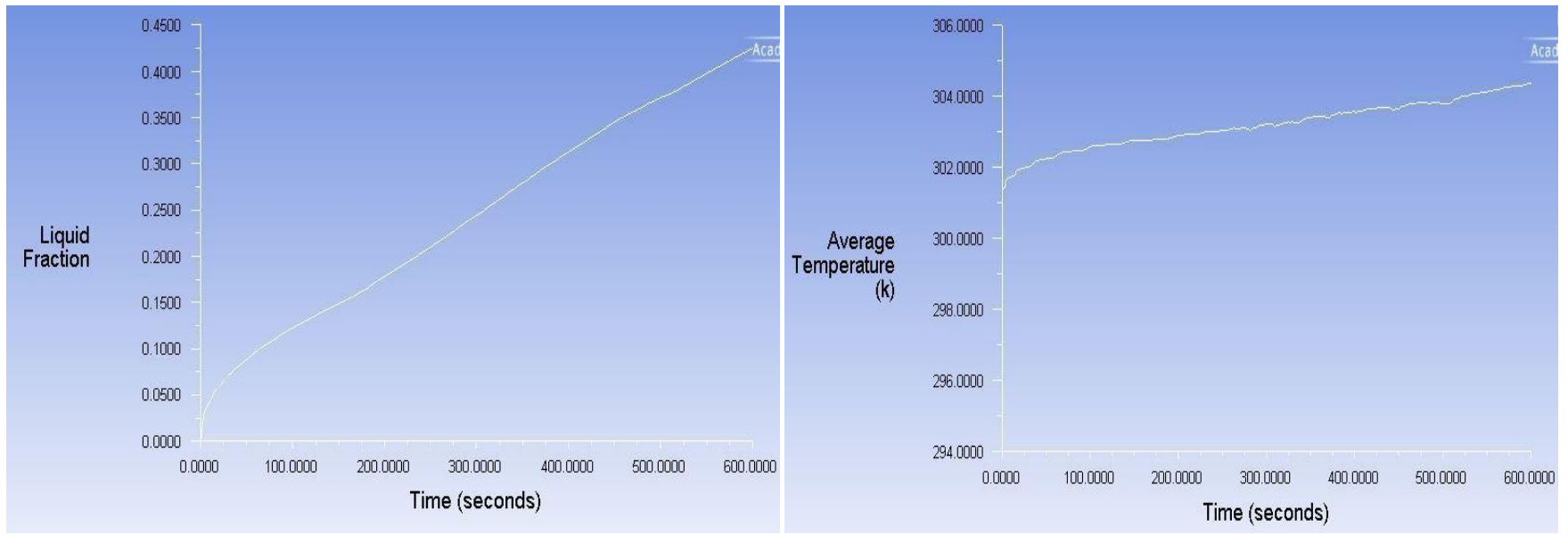

Figure 7: Liquid fraction vs time graph for melting of Gallium in a $90^{\circ}$ inclined enclosure.
Figure 8: Average temperature vs time graph for melting Gallium in a $90^{\circ}$ inclined enclosure.

At early melting stages the melt interface is almost flat and heat conduction is the main melting source. Later the interface shape becomes wavy and is controlled by convection currents to a large extent. As the 
conduction turns into convection many small vortices start originating overlapping each other increasing the turbulence in the flow. As the melting progresses they merge together with each other forming large sized vortices bringing back the 2-dimensionality of the flow (reduces the turbulence).

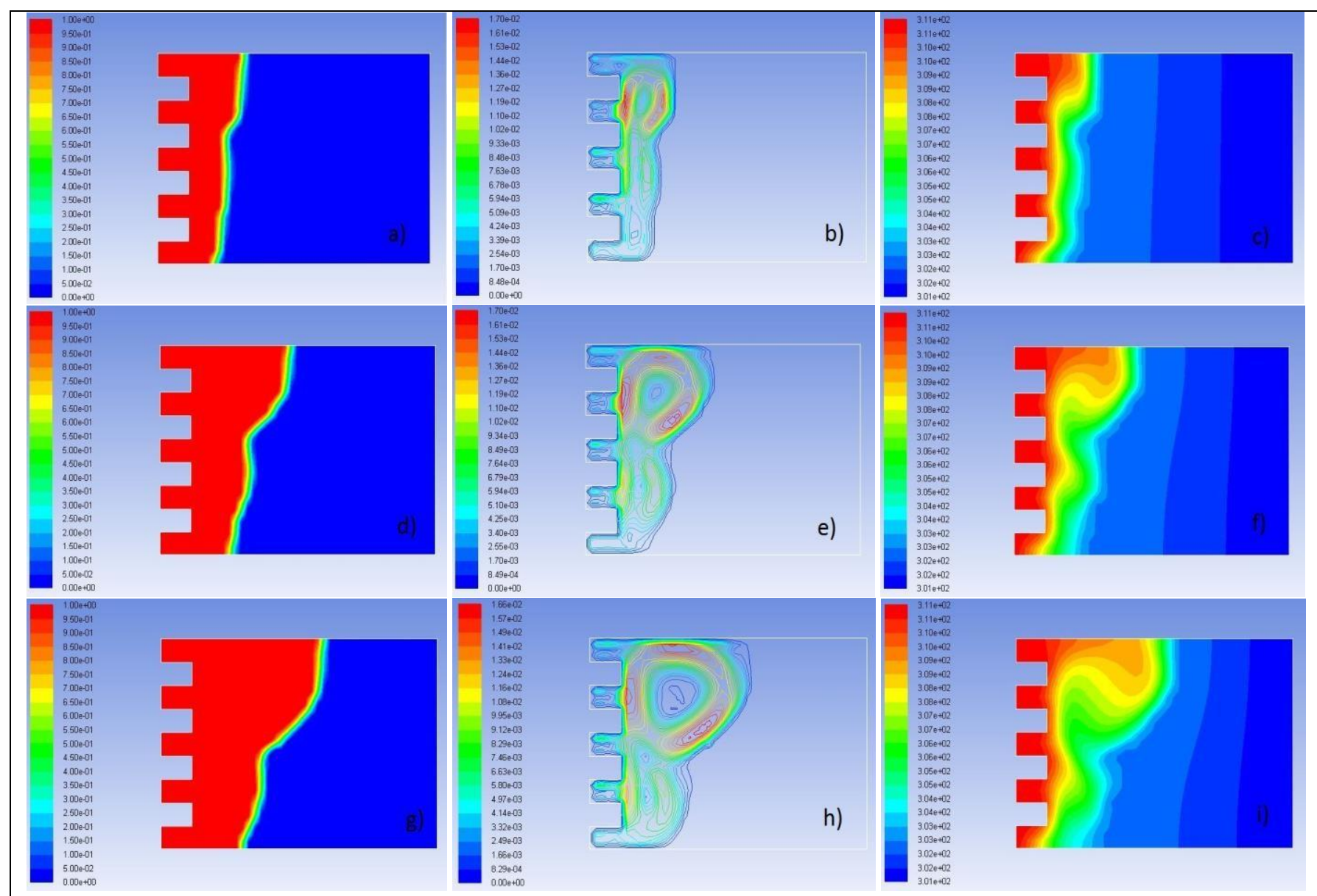

Figure 9: Melting of gallium in an enclosure with partial fins, after time, $t=180 \mathrm{~s}$ (top), $360 \mathrm{~s}$ (middle) and $540 \mathrm{~s}$ (bottom); $(a, d, g)$ are solid-liquid interface propagation, $(b, e, h)$ are stream lines and $(c, f, i)$ are isotherms.

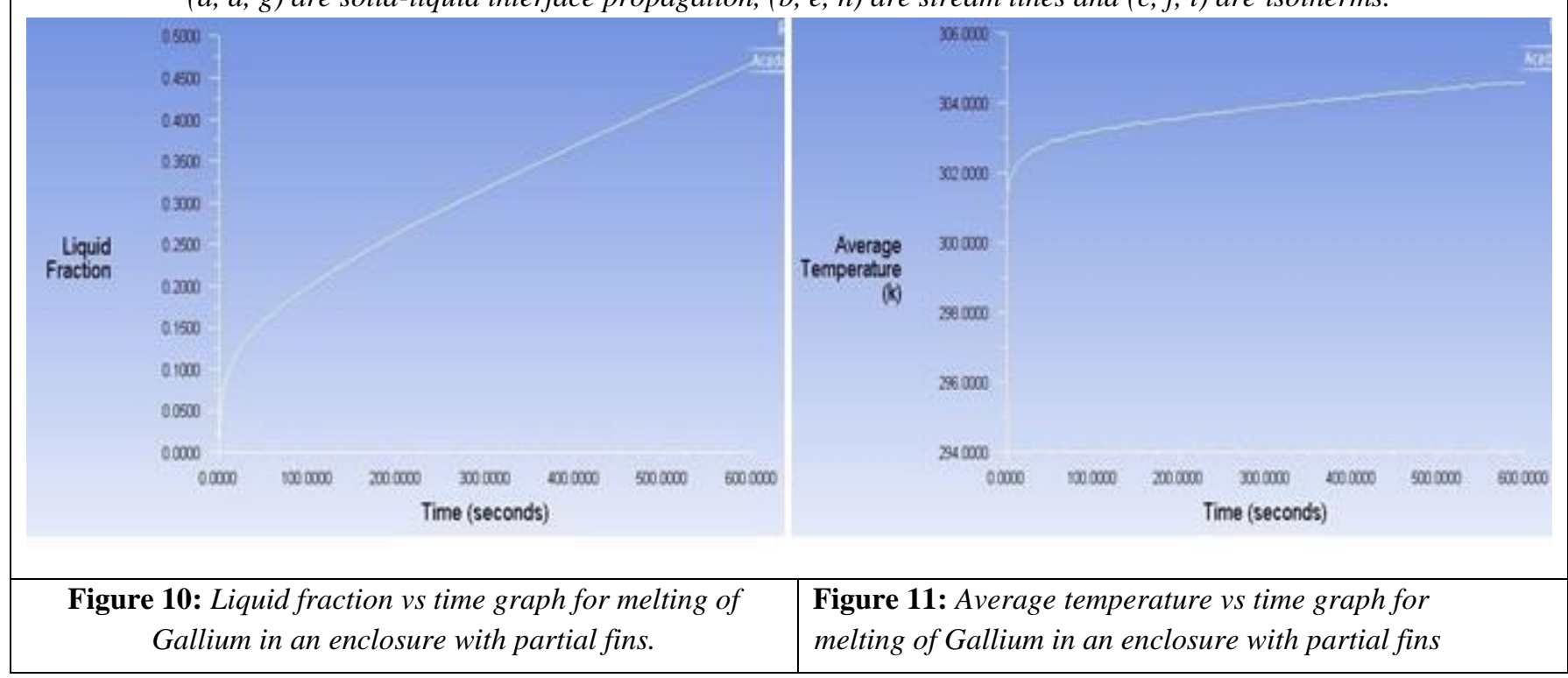

At early stages the melting is governed by heat conduction which changes to convection dominant. Buoyant forces dominate the viscous forces in order to do so. Increased surface area of heat transmission increases the melting rate. The liquid PCM rises along the wall and get diverted right by the fin where its separated 
Rao et al., J. Mod. Sim. Mater.; Vol. 1 Issue 1, pp: 30-38, 2018

into two streams. One directly impinges on the melt interface and the other rises along the tip to upper part of the enclosure. There will also thermal plumes originating from the top surface of the fin. The melting rate is enhanced by the vortex motion of thermally driven flows above the fin surfaces.

Initially the heat conduction dominant melting takes place due to viscous forces opposing the liquid flow. Later vortex induced melting occurs due to convection domination, which is caused by buoyancy forces domination over viscous forces. Direct impingement of thermal plumes originating from the hot wall on to the melt interface has some effect on melting rate. Large number of small vortices originate in the fin grooves and the hot surfaces. These combine to form large sized vortices as the time passes. A wavy type interface is formed at the beginning of the convection which is caused by the small sized vortex motions of the liquid. This increases the turbulence in the flow. As the melting time progresses these vortices mix with each other to form large sized vortices. As the vortices become large the waviness of the flow reduces decreasing the turbulence in the flow. Adding fins increased the vortex motion of the flow and surface area of the hot wall to boost the melting rate. Inclination increased the 3-dimensionality of the flow by generating more number of vortices and also produced thermal plumes, which effect the rate of melting in a great manner. One disadvantage of using the internal fins is that it reduces the amount of PCM that can be fit into a normal enclosure.

Table 2: Comparative tabulation of liquid fraction of all the four cases at different times.

\begin{tabular}{|c|c|c|c|c|}
\hline & \multicolumn{3}{|c|}{ Liquid Fraction } & Melting in an \\
\hline Time(seconds) & $\begin{array}{c}\text { Melting under } \\
\text { normal conditions }\end{array}$ & $\begin{array}{c}\text { Melting in a 90 } \\
\text { inclined enclosure }\end{array}$ & $\begin{array}{c}\text { Melting in a 90 } \text { inclined } \\
\text { enclosure with partial } \\
\text { fins } \\
\text { enclosure with partial } \\
\text { fins }\end{array}$ \\
\hline $180 \mathrm{~s}$ & 0.175 & 0.165 & 0.254 & 0.245 \\
\hline $360 \mathrm{~s}$ & 0.273 & 0.285 & 0.347 & 0.358 \\
\hline $540 \mathrm{~s}$ & 0.368 & 0.392 & 0.4375 & 0.464 \\
\hline $600 \mathrm{~s}$ & 0.400 & 0.425 & 0.442 & 0.493 \\
\hline
\end{tabular}

Table 3: Comparative tabulation of average temperature of all the four cases at different times.

\begin{tabular}{|c|c|c|c|c|}
\hline & & \multicolumn{2}{|c|}{ Average Temperature } & \\
\hline Time(seconds) & $\begin{array}{c}\text { Melting under } \\
\text { normal conditions }\end{array}$ & $\begin{array}{c}\text { Melting in a 90 } \\
\text { inclined enclosure }\end{array}$ & $\begin{array}{c}\text { Melting in an } \\
\text { enclosure with } \\
\text { partial } \\
\text { fins }\end{array}$ & $\begin{array}{c}\text { Melting in a 90 } \\
\text { inclined enclosure } \\
\text { with partial fins }\end{array}$ \\
\hline $180 \mathrm{~s}$ & $302.8 \mathrm{~K}$ & $302.75 \mathrm{~K}$ & $303.5 \mathrm{~K}$ & $303.5 \mathrm{~K}$ \\
\hline $360 \mathrm{~s}$ & $303.4 \mathrm{~K}$ & $303.4 \mathrm{~K}$ & $304.1 \mathrm{~K}$ & $304.0 \mathrm{~K}$ \\
\hline $540 \mathrm{~s}$ & $303.9 \mathrm{~K}$ & $304.05 \mathrm{~K}$ & $304.45 \mathrm{~K}$ & $304.6 \mathrm{~K}$ \\
\hline $600 \mathrm{~s}$ & $304.15 \mathrm{~K}$ & $304.45 \mathrm{~K}$ & $304.6 \mathrm{~K}$ & $304.8 \mathrm{~K}$ \\
\hline
\end{tabular}

From the results, plots and tables we can see that liquid fraction increased drastically when compared with normal conditions, inclined condition and internal fins. Average temperature has also increased significantly when compared to normal conditions. Thus, it is apt to say that the combined environment (inclination and internal fins) under normal gravity conditions has unparalleled effect on increasing melting rates which serves our purpose to extract large amount of energy in a short span of time. 
Study of Combined Effect of Inclination and Partial Fins on Melting of Phase Change Material................................ Using CFD

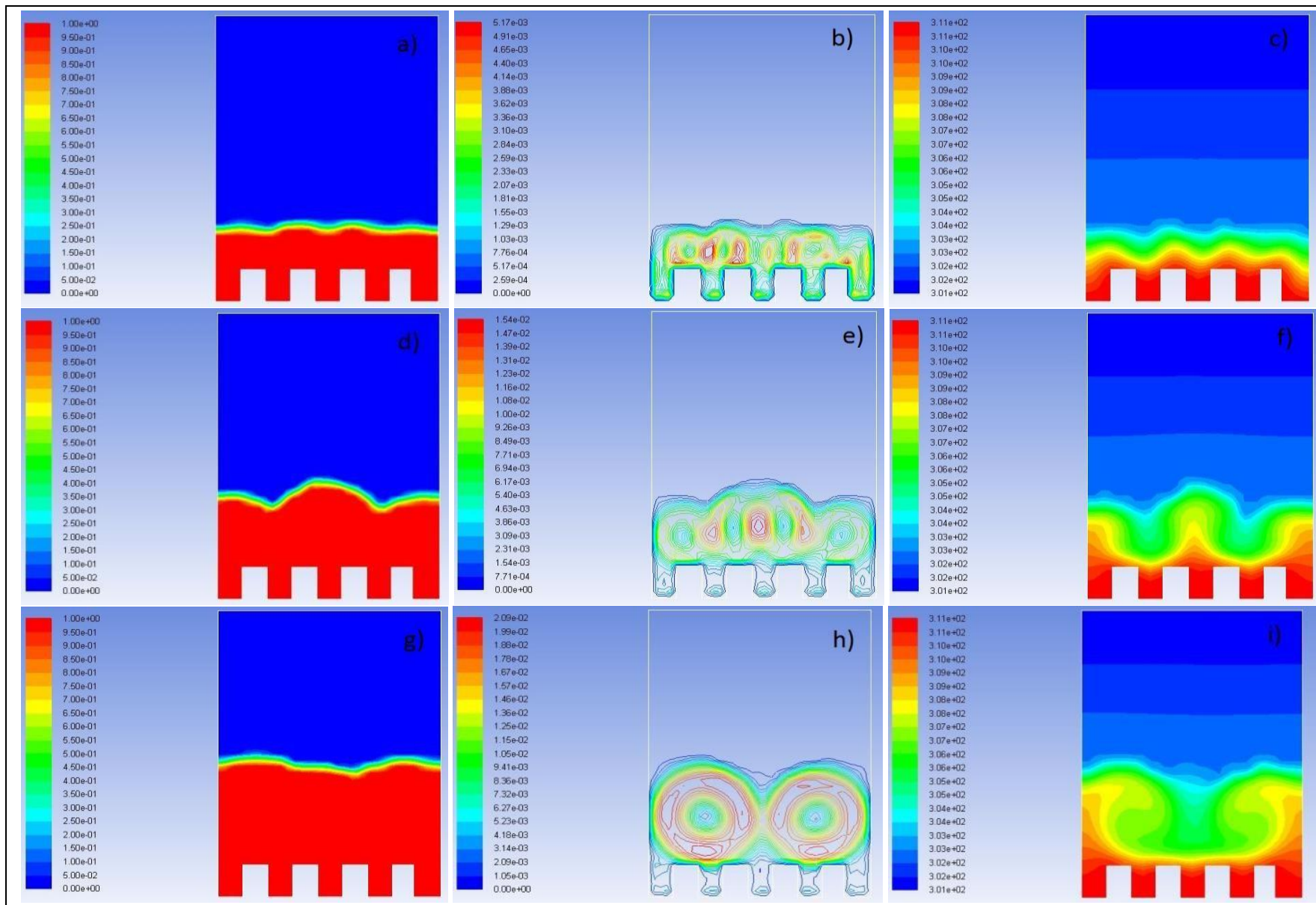

Figure 12: Melting of gallium in a $90^{\circ}$ inclined enclosure with partial fins, after time, $t=180 \mathrm{~s}$ (top), $360 \mathrm{~s}$ (middle) and $540 \mathrm{~s}$ (bottom); $(a, d, g)$ are solid-liquid interface propagation, $(b, e, h)$ are stream lines and $(c, f, i)$ are isotherms.

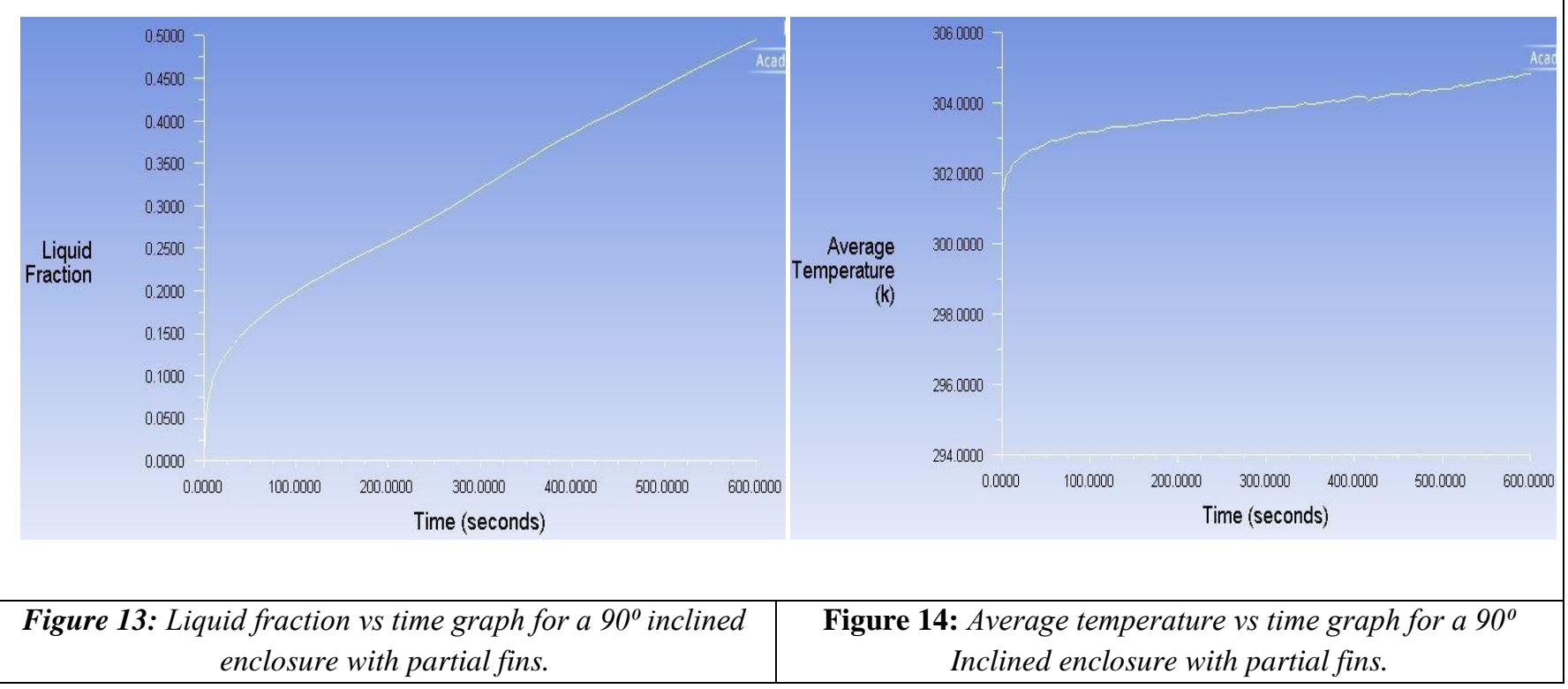

\section{Conclusions}

From this study we can conclude that both application of partial fins and providing inclination to the enclosure enhance the melting rate of PCM by empowering the heat transfer mechanisms. The initial conduction dominant melting is turned into convection dominant melting by the buoyant force's 
Rao et al., J. Mod. Sim. Mater.; Vol. 1 Issue 1, pp: 30-38, 2018

domination over viscous forces. The combined effect has increased the melting rate of PCM significantly by enhancing the convection currents. By using the combined effect of inclination and fins under normal gravity conditions we can extract large amount of energy from the PCM in a small time period, whose applications can be used extensively. If we take a step further and increase the gravity of the domain by applying electromagnetic field, we can get exceptional results.

\section{How to Cite this Article:}

D. Rao, S. Kolla, C. Sasanka, and D. Kumar, "Study of Combined Effect of Inclination and Partial Fins on Melting of Phase Change Material in A Rectangular Enclosure Using CFD”, J. Mod. Sim. Mater., vol. 1, no. 1, pp. 30-38, Dec. 2018. Doi: 10.21467/jmsm.1.1.30-38

\section{References}

[1] Liu, M.; Saman, W.; Bruno, F., (2012). Development of a novel refrigeration system for refrigerated trucks incorporating phase change material. Appl. Energy., 92, 336-342.

[2] Pistocchini, L.; Motta, M., (2011). Feasibility study of an innovative dry-cooling system with phase-change material storage for concentrated solar power multi-MW size power plant.J. of Solar Energy Engineering., 133( 3), pp: 10.

[3] Stritih, U.; Butala, V., (2010).Experimental investigation of energy saving in buildings with PCM cold storage. Int. J. Refrig., 33 , 1676-1683.

[4] Arunkumar, T.; Denkenberger, D.; Ahsan, A.; Jayaprakash, R., (2013) The augmentation of distillate yield by using concentrator coupled solar still with phase change material. Desalination, 314, 189-192.

[5] Kandasamy, R.; Wang, X., Mujumdar, A.S., (2007). Application of phase change materials in thermal management of electronics. Appl. Therm. Eng., 27 , 2822-2832.

[6] Varol, Y.; Okcu, M., (2013). Numerical investigation of fins effect for melting process of phase change materials. ASME 2013 International Mechanical Engineering Congress and Exposition, San Diego, California, USA, November 15-21, 2013.

[7] Liu, M,; Saman, W.; Bruno, F., (2014). Review on storage materials and thermal performance enhancement techniques for high temperature phase change thermal storage systems. Renewable and Sustainable Energy Reviews., 16 (4), $2118-2132$.

[8] Agyenim, F.; Hewitt, N.; Eames, P.; Smyth, M.,(2010) A review of materials, heat transfer and phase change problem formulation for latent heat thermal energy storage systems (LHTESS). Renewable and Sustainable Energy Reviews., 14 (2), $615-628$.

[9] BabakKamkari.; Hossein Shokouhmand.,(2014). Experimental investigation of phase change material melting in rectangular enclosures with horizontal partial fins. International Journal of Heat and Mass Transfer., 78, 839-851.

[10] Babak Kamkari, Hossein Shokouhmand.; Frank Bruno., (2014) Experimental investigation of the effect of inclination angle on convection-driven melting of phase change material in a rectangular enclosure. International Journal of Heat and Mass Transfer., 72 , 186-200.

[11] Brent, A.; Voller, V.; Reid, K.T.J., (1988) Enthalpy-porosity technique for modeling convection-diffusion phase change: Application to the melting of a pure metal. Numerical Heat Transfer-part A., 13 (3), 297-318.

Publish your research article in AIJR journals$\checkmark$ Online Submission and Tracking

$\checkmark$ Peer-Reviewed

$\checkmark$ Rapid decision

$\checkmark \quad$ Immediate Publication after acceptance

$\checkmark$ Articles freely available online

$\checkmark \quad$ Retain full copyright of your article.

Submit your article at journals.aijr.in
Publish your books with AIJR publisher-

$\checkmark \quad$ Publish with ISBN and DOI.

$\checkmark \quad$ Publish Thesis/Dissertation as a Book.

$\checkmark \quad$ Publish Monograph.

$\checkmark \quad$ Publish Edited Volume/ Book.

$\checkmark \quad$ Publish Conference Proceedings

$\checkmark \quad$ Retain full copyright of your books.

Submit your manuscript at books.aijr.org 